\title{
Gambaran Kualitas Fisik Lingkungan pada Ruang Dosen Gedung B PSDKU Universitas Airlangga
}

\author{
Yogi Yhuwono ${ }^{1}$ dan Septa Indra Puspikawati ${ }^{2}$ \\ ${ }^{1}$ Mahasiswa S1 Kesehatan Masyarakat PSDKU UNAIR \\ ${ }^{2}$ Dosen Program Studi Kesehatan Masyarakat PSDKU UNAIR \\ E-mail: yogi.yhuwono-2014@fkm.unair.ac.id
}

\begin{abstract}
Abstrak
Kondisi fisik lingkungan ruang yang tidak baik dapat menimbulkan risiko gangguan kesehatan berupa Sick Building Syndrome. Ruang dosen berpotensi mengalami masalah kualitas fisik lingkungan yang berdampak pada penghuninya karena banyak terdapat perabotan, tumpukan buku, perkakas, serta tingginya aktivitas perkantoran.Tujuan penelitian ini adalah untuk mengukur kualitas fisik lingkungan dan menggambarkan karakteristik ruang dosen gedung B PSDKU Universitas Airlangga di Banyuwangi. Penelitian ini merupakan penelitian observasional yang dianalisis secara deskriptif dengan pengumpulan data primer berupa pengamatan karakteristik ruangan, pengukuran temperatur, kelembaban, pencahayaan, dan kebisingan. Hasil penelitian menunjukkan bahwa pencahayaan (130,12 lux), kebisingan (52,18 dBA), dan kelembaban $(50,6 \%)$ telah memenuhi persyaratan baku mutu, sedangkan parameter temperatur sebesar $30^{\circ} \mathrm{C}$ melebihi dari persyaratan sesuai regulasi yaitu $18-28^{\circ} \mathrm{C}$. Disarankan melakukan perbaikan temperatur ruangan dengan pengendalian melalui penambahan ventilasi ruangan, baik alami maupun buatan.
\end{abstract}

Kata Kunci: Kualitas, Lingkungan, Ruang dosen

\section{DESCRIPTION OF PHYSICAL ENVIRONMENTAL QUALITY IN LECTURER'S ROOM B BUILDING PSDKU AIRLANGGA UNIVERSITY}

\begin{abstract}
Physical condition of the environment doesn't meet the standar can increase the health risks like Sick Building Syndrome. Lecturer's room have potential to get physical environmental quality problem that impact on staff because there are many furniture, piles of books, tools, and high office activity. The purpose of this study to measure the physical quality of the environment and to describe the characteristics of the lecturer's room of B building PSDKU Airlangga University in Banyuwangi. This research is an observational research which was analyzed descriptively by collecting primary data such as observation of room characteristic, temperature, humidity, lighting and noise. The result of research show that lighting (130,12 lux), noise (52,18 dBA), and humidity $(50,6 \%)$, that meet the quality standard requirements, while the temperature parameters of $30^{\circ} \mathrm{C}$ exceed those standard of $18-28^{\circ} \mathrm{C}$. It is recommended to improve the room temperature condition by controlling through room ventilation, both natural and artificial.
\end{abstract}

Keywords: Quality, Environmental, Lecturer's room 


\section{PENDAHULUAN}

Kualitas yang baik pada kondisi fisik lingkungan mampu menimbulkan rasa nyaman, memudahkan aktivitas, dan meningkatkan performansi penghuninya, sedangkan kondisi fisik lingkungan yang tidak baik dapat menimbulkan risiko gangguan kesehatan. Penelitian Sedarmayanti dan Nursiswanto (2014) pada Dinas Tenaga kerja Transmigrasi dan Sosial Kota Cimahi dibuktikan bahwa selain kondisi fisik lingkungan, terdapat pengaruh sebesar $35,4 \%$ antara tata ruang kantor terhadap kinerja. Prasasti et al (2013) menyebutkan bahwa kondisi bangunan yang buruk dan tidak optimal dapat mengakibatkan dampak berupa Sick Building Syndrome (SBS). Hartoyo (2009) menjelaskan bahwa Sick Building Syndrome adalah suatu kumpulan gejala yang diderita oleh tenaga kerja pada laboratorium, perkantoran, supermarket dan bangunan lain dengan lebih dari satu gejala seperti kelelahan, sakit kepala, kesulitan konsentrasi, dan gangguan pernapasan.

Kondisi fisik lingkungan kerja yang tidak baik berpotensi menjadi determinan bagi tenaga kerja untuk mudah stres, mudah jatuh sakit, sulit konsentrasi, dan penurunan produktivitas (Pratiwi dan Wahyuningtyas, 2014). Terbukti pada penelitian yang dilakukan Norianggono et al (2014) dihasilkan bahwa variabel lingkungan kerja fisik memiliki pengaruh yang signifikan terhadap kinerja karyawan pada lokasi penelitian yang dilakukan. Cintia dan Gilang (2016) juga membuktikan hal tersebut melalui penelitiannya yang diketahui bahwa sebesar 44,9\% pengaruh lingkungan kerja fisik terhadap kinerja dari pekerja.

Sumber penyebab gangguan lingkungan dalam ruang antara lain perlengkapan dalam bangunan (AC, almari, dan lain-lain), kelembaban, kondisi bangunan, temperatur, pertukaran udara, dan hal-hal yang terkait dengan perilaku penghuni ruang, misalnya merokok (Fitria et al, 2008). Berdasarkan studi pendahuluan (2017), diketahui bahwa faktor gangguan lingkungan juga ditemukan pada ruang dosen gedung $B$ PSDKU Universitas Airlangga di Banyuwangi. Banyaknya perabotan, tumpukan buku, perkakas, alat elektronik, dan tingginya aktivitas perkantoran berpotensi tinggi menjadi gangguan lingkungan fisik bagi penghuninya.

Oleh karena itu, berdasarkan uraian latar belakang tersebut, penelitian ini bertujuan untuk menggambarkan karakteristik ruang dosen gedung B PSDKU Universitas Airlangga di Banyuwangi yang terdiri atas luas ruang, jendela, lampu, dinding, lantai, perabotan ruang, dan AC. Selain itu, penelitian ini juga bertujuan untuk mengukur kualitas fisik lingkungan pada ruangan yang terdiri atas temperatur, kelembaban, pencahayaan, dan kebisingan ruangan.

\section{METODE}


Penelitian ini merupakan penelitian observasional deskriptif yang dilaksanakan di ruang dosen gedung B PSDKU Universitas Airlangga di Banyuwangi pada 12 Mei 2017 pukul 08:00-13:00. Pengumpulan data primer dilakukan pada variabel karakteristik ruangan, pencahayaan, kebisingan, temperatur, dan kelembaban. Pengamatan karakteristik ruangan dibantu dengan lembar observasi untuk menggambarkan luas ruang, jendela, lampu, dinding, lantai, perabotan ruang, dan AC dalam ruangan. Pengukuran pencahayaan menggunakan Lux Meter, kebisingan menggunakan Sound Level Meter, suhu dan kelembaban menggunakan thermohygrometer.

Pengukuran pencahayaan sesuai ketentuan Standar Nasional Indonesia Nomor 16-7062-2004 pada 6 titik ruang yang dilakukan pengulangan sebanyak 4 kali. Sedangkan pengukuran kebisingan juga pada 6 titik yang terdiri atas setiap sudut ruang dan 2 titik di tengah ruang yang dilakukan 4 kali ulangan. Pengukuran suhu dan kelembaban pada ruangan dilakukan pada setiap sudut ruang untuk merepresentasikan kondisi ruangan dengan ulangan sebanyak 4 kali. Analisis data secara deskriptif dilakukan dengan menggambarkan hasil pengamatan dan rata-rata hasil pengukuran.

\section{HASIL DAN PEMBAHASAN}

Ruang dosen gedung B PSDKU Universitas Airlangga di Banyuwangi terletak di lantai 2 pada gedung milik SMKN 1 Banyuwangi dengan luas $69,92 \mathrm{~m}^{2}$ terdiri dari panjang 9,2 meter dan lebar 7,6 meter. Ruang dosen tersebut menjadi ruang kerja bagi 8 orang dosen. Berdasarkan penelitian yang dilakukan, maka didapatkan hasil sesuai dengan Gambar 1 yang menggambarkan hasil pengamatan, selain itu tabel 1 hingga tabel 4 menggambarkan ratarata hasil pengukuran.

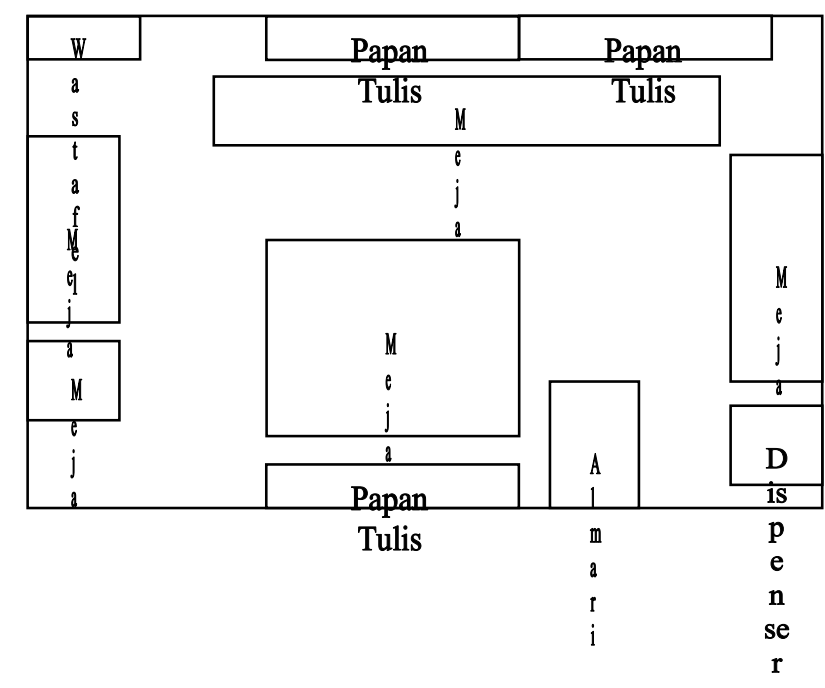

Gambar 1. Denah penempatan meja perabotan 
Tabel 1. Hasil pengukuran pencahayaan

\begin{tabular}{cccccccc}
\hline Ulangan & Titik 1 & Titik 2 & Titik 3 & Titik 4 & Titik 5 & Titik 6 & Rata-rata \\
\hline 1 & $158 \operatorname{lux}$ & $172 \operatorname{lux}$ & $83 \operatorname{lux}$ & $208 \operatorname{lux}$ & $79 \operatorname{lux}$ & $74 \operatorname{lux}$ & \\
\cline { 1 - 5 } 2 & $162 \operatorname{lux}$ & $168 \operatorname{lux}$ & $82 \operatorname{lux}$ & $206 \operatorname{lux}$ & $96 \operatorname{lux}$ & $73 \operatorname{lux}$ & 130,12 lux \\
\hline 3 & $161 \operatorname{lux}$ & $171 \operatorname{lux}$ & $82 \operatorname{lux}$ & $207 \operatorname{lux}$ & $83 \operatorname{lux}$ & $73 \operatorname{lux}$ & \\
\hline 4 & $156 \operatorname{lux}$ & $186 \operatorname{lux}$ & $81 \operatorname{lux}$ & $210 \operatorname{lux}$ & $80 \operatorname{lux}$ & $72 \operatorname{lux}$ & \\
\hline
\end{tabular}

Sumber data: data primer

Tabel 2. Hasil pengukuran kebisingan

\begin{tabular}{|c|c|c|c|c|c|c|c|}
\hline Ulangan & Titik 1 & Titik 2 & Titik 3 & Titik 4 & Titik 5 & Titik 6 & Rata-rata \\
\hline \multirow{2}{*}{1} & 52.53 & 51.30 & 49.55 & 51.13 & 52.52 & 54.83 & \multirow{8}{*}{$52.18 \mathrm{dBA}$} \\
\hline & $\mathrm{dBA}$ & $\mathrm{dBA}$ & $\mathrm{dBA}$ & $\mathrm{dBA}$ & $\mathrm{dBA}$ & $\mathrm{dBA}$ & \\
\hline \multirow{2}{*}{2} & 51.53 & $\begin{array}{l}55.70 \\
\end{array}$ & 49.35 & 51.57 & 53.35 & 53.93 & \\
\hline & $\mathrm{dBA}$ & $\mathrm{dBA}$ & $\mathrm{dBA}$ & $\mathrm{dBA}$ & $\mathrm{dBA}$ & $\mathrm{dBA}$ & \\
\hline \multirow{2}{*}{3} & 50.10 & 56.23 & 50.82 & 50.15 & 54.62 & 50.98 & \\
\hline & $\mathrm{dBA}$ & $\mathrm{dBA}$ & $\mathrm{dBA}$ & $\mathrm{dBA}$ & $\mathrm{dBA}$ & $\mathrm{dBA}$ & \\
\hline \multirow{2}{*}{4} & 51.75 & $\begin{array}{l}55.98 \\
\end{array}$ & 50.32 & 48.72 & 52.67 & 52.72 & \\
\hline & dBA & $\mathrm{dBA}$ & dBA & $\mathrm{dBA}$ & $\mathrm{dBA}$ & dBA & \\
\hline
\end{tabular}

Sumber data: data primer

Tabel 3. Hasil pengukuran temperatur

\begin{tabular}{|c|c|c|c|c|c|}
\hline Ulangan & Titik 1 & Titik 2 & Titik 3 & Titik 4 & Rata-rata \\
\hline 1 & $30,3^{\circ} \mathrm{C}$ & $30,1^{\circ} \mathrm{C}$ & $30,4^{\circ} \mathrm{C}$ & $30,4^{\circ} \mathrm{C}$ & \multirow{4}{*}{$30,27^{\circ} \mathrm{C}$} \\
\hline 2 & $30,3^{\circ} \mathrm{C}$ & $30,1^{\circ} \mathrm{C}$ & $30,4^{\circ} \mathrm{C}$ & $30,3^{\circ} \mathrm{C}$ & \\
\hline 3 & $30,4^{\circ} \mathrm{C}$ & $30,4^{\circ} \mathrm{C}$ & $30,3^{\circ} \mathrm{C}$ & $30,1^{\circ} \mathrm{C}$ & \\
\hline 4 & $30,2^{\circ} \mathrm{C}$ & $30,2^{\circ} \mathrm{C}$ & $30,2^{\circ} \mathrm{C}$ & $30,2^{\circ} \mathrm{C}$ & \\
\hline
\end{tabular}

Sumber data: data primer

Tabel 4. Hasil pengukuran kelembaban

\begin{tabular}{cccccc}
\hline Ulangan & Titik 1 & Titik 2 & Titik 3 & Titik 4 & Rata-rata \\
\cline { 1 - 5 } 1 & $48 \%$ & $43 \%$ & $50 \%$ & $55 \%$ & \\
\cline { 1 - 4 } 2 & $48 \%$ & $43 \%$ & $59 \%$ & $55 \%$ & \multirow{2}{*}{$50,6 \%$} \\
\cline { 1 - 4 } 3 & $55 \%$ & $59 \%$ & $48 \%$ & $44 \%$ & \\
\cline { 1 - 4 } & $49 \%$ & $47 \%$ & $51 \%$ & $56 \%$ & \\
\hline
\end{tabular}

Sumber data: data primer 


\section{Karakteristik Ruang}

Ruang dosen gedung B PSDKU Universitas Airlangga di Banyuwangi memiliki jendela pada bagian selatan dan utara ruang yang dalam kondisi tertutup oleh gorden, papan tulis, dan almari (Gambar 1). Jendela diposisikan berderet pada kedua sisi dan sebagian diantaranya merupakan jendela yang tidak dapat dibuka. Lampu terpasang sebanyak 6 buah dan bukan termasuk jenis lampu LED. Pemasangan lampu berada pada posisi yang merata pada seluruh ruang serta dalam kondisi menyala. Air Conditioner (AC) berjumlah 2 buah yang terpasang di dinding atas bagian utara ruang dosen.

Dinding ruang dosen memiliki konstruksi berkondisi baik dan terdiri dari penyangga beton serta dikelilingi batu bata dengan cat tembok putih. Lantai dilapisi oleh keramik berwarna abu-abu berbentuk persegi dengan sisi $40 \mathrm{~cm}$. Ruang dosen diisi oleh berbagai perabotan yang terdiri dari meja dosen beserta kursinya dan meja diskusi (Gambar 1) yang terbuat dari kayu berlapis plastik, terdapat juga papan tulis whiteboard, kemudian dilengkapi almari, printer, komputer, wastafel, dispenser, serta buku dan dokumen yang menumpuk pada meja dosen. Pada ruang dosen terdapat 8 meja dosen yang berjajar pada bagian barat, utara, dan timur ruang (Gambar 1). Kemudian terdapat meja komputer dan printer yang berdekatan dengan pintu masuk, serta meja diskusi yang merupakan gabungan beberapa meja pada bagian tengah sisi selatan ruang.

Papan tulis pada dinding selatan dan berhadapan langsung dengan meja diskusi yang menutup jendela bagian selatan. Papan tulis juga teletak pada dinding utara (Gambar 1) terdiri dari 2 buah papan tulis yang juga menutup jendela bagian utara. Almari berbahan dasar besi yang berisi dokumen diletakkan pada sisi timur meja diskusi dan menjadi sekat untuk tempat melangsungkan ibadah pada ujung timur ruang. Pada bagian ini juga terdapat dispenser air minum sebagai bagian pemenuhan kebutuhan air minum dosen. Wastafel diletakkan pada ujung utara ruang bagian barat yang dilengkapi dengan kran, pengering tangan, dan sabun pencuci tangan.

Ruang dosen gedung B PSDKU Universitas Airlangga di Banyuwangi menjadi ruang kerja bagi 8 orang dosen yang artinya berdasarkan luas ruang telah memenuhi ketentuan sesuai Keputusan Menteri Kesehatan Republik Indonesia Nomor 1405/ MENKES/ SK/ XI/ 2002 yaitu minimal $10 \mathrm{~m}^{3}$ ruang udara untuk setiap karyawan. Kemudian regulasi tersebut juga menjelaskan bahwa pada ruang perkantoran diupayakan mendapat pergantian udara secara alamiah dengan cara membuka seluruh pintu dan jendela, namun hal ini yang tidak dilakukan pada ruang dosen bahkan jendela ditutup menggunakan perabot lain. Kondisi demikian mengakibatkan ruang dosen tidak mendapatkan suplai penghawaan alami 
dari luar ruang dan harus mengandalkan ventilasi buatan yaitu Air Conditioner (AC).

Kondisi tertutup pada jendela juga berimplikasi pada penggunaan penerangan buatan pada ruang dosen. Pencahayaan yang berasal dari lampu telah dilakukan pertimbangan terkait jumlah dan jarak penempatan lampu, sehingga tidak menimbulkan kesilauan sesuai ketentuan regulasi. Selanjutnya cat tembok berwarna putih telah sesuai dengan regulasi yaitu bersih dan berwarna terang. Penggunaan keramik sebagai permukaan lantai menjadi pilihan yang tepat terkait ketentutan persyaratan kesehatan lingkungan perkantoran yang mengharuskan lantai kedap air, dari bahan yang kuat, permukaan rata, tidak licin, dan bersih.

\section{Pencahayaan Ruang}

Hasil pengukuran menunjukkan bahwa pencahayaan rata-rata ruang dosen dengan kondisi seluruh lampu menyala adalah 130,12 lux (Tabel 1). Oleh karena itu, parameter pencahayaan telah memenuhi persyaratan kesehatan lingkungan perkantoran sesuai Keputusan Menteri Kesehatan Nomor 1405 Tahun 2002 yaitu minimal 100 lux.

Faktor intensitas pencahayaan mampu memberikan pengaruh yang berarti terhadap waktu penyelesaian pekerjaan (Setyanto, 2011). Sholehah (2014) juga mengungkapkan bahwa pencahayaan berpengaruh positif terhadap semangat bekerja dari pekerja. Terpenuhinya parameter pencahayaan dapat Jurnal Kesehatan Poltekkes Ternate menjadi upaya pencegahan terkait dengan dampak yang ditimbulkan oleh rendahnya pencahayaan. Sari (2016) menjelaskan pencahayaan yang didesain dengan tidak baik maka menimbulkan gangguan dan kelelahan penglihatan saat bekerja hingga berkurangnya daya dan efisiensi kerja.

\section{Kebisingan Ruang}

Hasil pengukuran menunjukkan bahwa kebisingan rata-rata ruang dosen adalah 52,18 dBA (Tabel 2). Oleh karena itu, parameter kebisingan juga memenuhi persyaratan kesehatan lingkungan perkantoran sesuai Keputusan Menteri Kesehatan Nomor 1405 Tahun 2002 yaitu maksimal 85 dBA.

Terpenuhinya parameter kebisingan pada ruang dosen mampu meminimalkan risiko gangguan kesehatan akibat kebisingan. Hal tersebut sesuai dengan yang dijelaskan oleh Mukono (2006) bahwa kebisingan dapat menimbulkan risiko efek terhadap pendengaran dan juga efek bukan pendengaran seperti stress, kelelahan, perubahan penampilan, dan gangguan komunikasi. Pengaruh utama kebisingan adalah adanya kerusakan pada indra pendengar, baik tuli progresif maupun tuli permanen (Sari, 2016).

\section{Temperatur Ruang}

Hasil pengukuran menunjukkan bahwa temperatur rata-rata ruang dosen dengan kondisi Air Conditioner menyala adalah 30,27 ${ }^{\circ} \mathrm{C}$ (Tabel 3). Oleh karena itu, parameter 
temperatur belum memenuhi persyaratan kesehatan lingkungan perkantoran sesuai dengan Keputusan Menteri Kesehatan Nomor 1405 Tahun 2002 yaitu $18^{\circ} \mathrm{C}-28^{\circ} \mathrm{C}$.

Yulianti et al., (2012) menyebutkan bahwa suhu ruang dapat mempengaruhi saraf sensorik membran mukosa dan kulit serta memberikan respon neurosensoral yang mengakibatkan perubahan sirkulasi darah. Bahkan pada penelitian Ardian dan Sudarmaji (2014) diketahui bahwa terdapat pengaruh berupa risiko eye tiredness pada lingkungan kerja yang panas. Suhu panas juga mengganggu kecermatan kerja otak, mengurangi kelincahan, mengganggu koordinasi syaraf perasa dan motoris, serta memperpanjang waktu reaksi dan waktu pengambilan keputusan (Fauzi, 2015). Penelitian Sari (2016) yang dilakukan pada karyawan kolektor gerbang tol Cengkareng dibuktikan bahwa ada hubungan antara suhu ruangan dengan kelelahan kerja.

Oleh karena itu, sirkulasi udara perlu dioptimalkan untuk dapat mengurangi parameter suhu pada ruang dosen. Alternatif pengendalian suhu dapat melalui ventilasi buatan seperti penambahan Air Conditioner (AC) maupun penurunan suhu pada remote Air Conditioner. Cara lain dalam pengendalian suhu adalah menggunakan sirkulasi udara alami dengan dibukanya jendela yang tersedia (Fauzi, 2015).

\section{Kelembaban Ruang}

Hasil pengukuran menunjukkan bahwa kelembaban rata-rata ruang dosen dengan kondisi Air Conditioner menyala adalah 50,6\% (Tabel 4). Oleh karena itu, parameter kelembaban telah memenuhi persyaratan kesehatan lingkungan perkantoran sesuai Keputusan Menteri Kesehatan Nomor 1405 Tahun 2002 yaitu $40 \%$ - 60\%.

Kelembaban secara bersamaan dengan suhu, kecepatan udara, dan radiasi panas mempengaruhi keadaan tubuh pada saat menerima atau melepaskan panas (Sari, 2016). Terpenuhinya parameter kelembaban dapat menanggulangi dampak buruk dari kelembaban yang tidak optimal seperti diungkapkan oleh Hartoyo (2009) yaitu kelembaban yang kurang dari $20 \%$ dapat menyebabkan kekeringan selaput lendir membran. Sedangkan kelembaban yang tinggi pada suhu tinggi dapat meningkatkan pertumbuhan mikroorganisme dan pelepasan formaldehid dari material bangunan (Hartoyo, 2009).

\section{KESIMPULAN}

Ketersediaan ruang udara, kondisi bangunan, pemilihan cat tembok, penggunaan keramik sebagai lantai merupakan beberapa karakteristik ruang dosen gedung B PSDKU Universitas Airlangga di Banyuwangi yang telah memenuhi ketentuan dari Keputusan Menteri Kesehatan Nomor 1405/MENKES/SK/XI/2002.

Hasil pengukuran menunjukkan bahwa rata-rata pencahayaan adalah 130,12 lux, rata- 
rata kebisingan adalah 52,18 dBA, dan rata-rata kelembaban adalah 50,6\%. Ketiganya telah memenuhi regulasi sesuai Keputusan Menteri Kesehatan Nomor 1405/MENKES/SK/XI/2002, sedangkan parameter temperatur sebesar $30^{\circ} \mathrm{C}$ melebihi dari persyaratan yang seharusnya $18-28^{\circ} \mathrm{C}$. Pemenuhan ketentuan secara optimal akan meningkatkan kualitas fisik lingkungan, sehingga mampu menimbulkan rasa nyaman, memudahkan aktivitas, dan meningkatkan performansi penghuninya.

\section{DAFTAR PUSTAKA}

Ardian, A. E., dan Sudarmaji. 2014. Faktor yang Memengaruhi Sick Builidng Syndromedi Ruagan Kantor. Jurnal Kesehatan Lingkungan, 7(2), 107-117

Cintia, E., dan Gilang, A., 2016. Pengaruh Lingkungan Kerja Fisik dan Nonfisik terhadap Kinerja Karyawan pada KPPN Bandung I. Jurnal Sosioteknologi, 15(1), 136-154

Fauzi, M., 2015. Hubungan Faktor Fisik, Biologi dan Karakteristik Individu dengan Kejadian Sick Building Syndrome pada Pegawai di Gedung Pandanaran Kota Semarang. Universitas Negeri Semarang, Semarang, Indonesia Fitria, L., et al., 2008. Kualitas Udara dalam Ruang Perpustakaan Universitas " $\mathrm{X}$ " ditinjau dari Kualitas Biologi, Fisik, dan Kimiawi. Makara Kesehatan, 12(2)
Hartoyo, S., 2009. Faktor Lingkungan yang Berhubungan dengan Kejadian Sick Building Syndrome (SBS) di Pusat Laboratorium Forensik dan Uji Balistik MABES POLRI. Universitas Diponegoro, Semarang, Indonesia

Kementerian Kesehatan RI, 2002. Keputusan Menteri Kesehatan Republik Indonesia Nomor 1405/MENKES/SK/XI/2002 tentang Persyaratan Kesehatan Lingkungan Kerja Perkantoran dan Industri. Jakarta: Kementerian Kesehatan Republik Indonesia

Kementerian Tenaga Kerja dan Transmigrasi Republik Indonesia, 2011. Nilai Ambang Btas Faktor Fisika dan Faktor Kimia di Tempat Kerja. Jakarta: Kementerian Tenaga Kerja dan Transmigrasi Republik Indonesia

Mukono, H. J., 2006. Prinsip dasar kesehatan lingkungan edisi kedua. Surabaya: Airlangga University Press

Norianggono, Y. C. A P., et al., 2014. Pengaruh Lingkungan Kerja Fisik dan Non Fisik terhadap Kinerja Karyawan (Studi pada Karyawan PT.Telkomsel Area III JawaBali Nusra Di Surabaya). Jurnal Administrasi Bisnis (JAB), 8(2), 1-10

Prasasti, C. I., et al., 2013. Kualitas Udara dalam Ruang Kelas ber-AC dan Keluhan Kesehatan Siswa. Jurnal Kesehatan Lingkungan, 7(1)

Pratiwi, D. M., dan Wahyuningtyas, R., 2014. Pengaruh Lingkungan Kerja Fisik Volume 11 Nomor 1 Tahun 2018 
terhadap Stres Kerja Karyawan (Studi

Pada PT Krakatau Steel (Persero) Tbk.

Divisi CRM). Universitas Telkom, Indonesia

Sari, O. A. P., 2016. Hubungan Lingkungan Kerja Fisik dengan Kelelahan Kerja pada Kolektor Gerbang Tol Cililitan PT Jasa Marga Cabang Cawang Tomang Cengkareng tahun 2016. Universitas Islam Negeri Syarif Hidayatullah, Jakarta, Indonesia

Sedarmayanti, dan Nursiswanto, E., 2014. Pengaruh Ruang Kantor terhadap Kinerja Pegawai Dinas Tenaga Kerja
Transmigrasi Sosial Kota Cimahi. Jurnal Ilmu Administrasi, 11(3), 501-510

Setyanto, R, H., 2011. Pengaruh Faktor Lingkungan Fisik Kerja terhadap Waktu Penyelesaian Pekerjaan: Studi Laboratorium. Performa, 10(1), 19-28 Sholehah, K., 2014. Studi tentang Pengaruh Lingkungan Kerja terhadap Semangat Kerja Pegawai di Kantor Kecamatan Waru Kabupaten Penajam Paser Utara. eJournal Ilmu Pemerintahan, 2(2), 27292740

Yulianti, D., et al. 2012. Sick Building Syndrome. $C D K-189,39(1)$ 